\title{
Beliefs of parents in Kuwait about thirdhand smoke and its relation to home smoking rules: A cross-sectional study
}

\author{
Kawthar Shehab ${ }^{1}$, Ali H. Ziyab ${ }^{1}$
}

\begin{abstract}
INTRODUCTION Thirdhand smoke (THS) is the toxic residue of tobacco smoke that persists long after tobacco smoking on the clothing and hair of smokers and in the surrounding environment. This study aimed to assess parents' beliefs about THS in terms of harm and persistence in the environment and evaluate associations between parents' THS beliefs and home smoking rules.

METHOds A sample of parents living in Kuwait were enrolled in a cross-sectional study. Parents reported home smoking rules (strict, partial, and no, home smoking ban) and completed the 9-item Beliefs About ThirdHand Smoke (BATHS) scale that assessed parents' overall, health, and persistence beliefs about THS. Associations between the quartiles of THS overall, health, and persistence beliefs scores and home smoking rules were evaluated using a modified Poisson regression, and adjusted prevalence ratios (APR) and 95\% confidence intervals (CI) were estimated.

RESULTS In total, 536 parents (404 females) were enrolled in the study, with $42.0 \%$ $(n=225)$ and $43.6 \%(n=234)$ reporting a strict or partial home smoking ban, respectively. The prevalence of a strict home smoking ban was higher among never smokers than among ever smokers $(49.1 \%$ vs $25.2 \%$, p $<0.001)$. The majority of participants indicated that THS exposure harms the health of children (67.2\%) and adults $(60.6 \%)$ and THS residue could remain for days in the environment (58.9\%). The prevalence of a strict home smoking ban increased as THS overall $\left(\mathrm{APR}_{\mathrm{Q} 4 \mathrm{vs} Q 1}=1.48 ; 95 \% \mathrm{CI}: 1.12-1.96\right)$, health $\left(\mathrm{APR}_{\mathrm{Q} 4 \mathrm{vs} Q 1}=1.22 ; 1.02-1.45\right)$, and persistence $\left(\mathrm{APR}_{\mathrm{Q} 4 \mathrm{vs} Q 1}=1.55 ; 1.17-2.05\right)$ beliefs scores increased.

conclusions Parents' harm and persistence beliefs about THS were associated with enforcing a strict home smoking ban, which provides a safer environment for children and non-smokers. Therefore, tobacco prevention programs need to incorporate educational messages about the harm of THS in an attempt to promote smoke-free homes.
\end{abstract}

\author{
AFFILIATION \\ 1 Department of Community \\ Medicine and Behavioral \\ Sciences, Faculty of Medicine, \\ Kuwait University, Kuwait \\ City, Kuwait \\ CORRESPONDENCE TO \\ Ali H. Ziyab. Department \\ of Community Medicine \\ and Behavioral Sciences, \\ Faculty of Medicine, Kuwait \\ University, Safat 13110, \\ Kuwait City, Kuwait. E-mail: \\ aziyab@hsc.edu.kw \\ ORCID ID: https://orcid. \\ org/0000-0003-3099-4424
}

KEYWORDS parents, beliefs, Kuwait, thirdhand smoke, home smoking ban

Received: 26 March 2021 Revised: 6 June 2021 Accepted: 8 July 2021

\section{INTRODUCTION}

Thirdhand smoke (THS) has been recognized as a public health hazard that is distinct from secondhand smoke (SHS). Matt et al. ${ }^{1}$ defined THS in 2011 as 'residual tobacco smoke pollutants that remain on surfaces and in dust after tobacco has been smoked, are re-emitted into the gas phase, or react with oxidants and other compounds in the environment to yield secondary pollutants'. On the other hand, secondhand smoke (SHS), an established and serious health hazard ${ }^{2,3}$, consists of a 'mixture of the sidestream smoke (i.e. smoke emitted from the burning cigarette, pipe, or cigar) and the mainstream smoke exhaled from the lungs of smokers'. Hence, children and non-smoker adults experience SHS exposure by involuntary inhalation of sidestream 
and exhaled mainstream smoke. Exposure to THS occurs after cigarettes/tobacco products have been extinguished through involuntary inhalation, ingestion, or dermal absorption of residual tobacco smoke pollutants that persist long after the clearing of SHS ${ }^{4,5}$. Collectively, as proposed by Protano and Vitali ${ }^{4}$, the term 'environmental tobacco smoke' (ETS) or 'passive smoking' should be used to describe both SHS and THS (i.e. exposure to tobacco smoke pollutants during [SHS] and after [THS] tobacco smoking). SHS and THS are distinct and major sources of involuntary exposure to tobacco smoke pollutants that may predispose children and nonsmoker adults to adverse health effects.

Previous studies have shown that THS is present on the smokers' clothes, skin, and hair, as well as on household surfaces such as walls, beds, couches, carpets, and desks ${ }^{6-8}$. Contaminants of THS include carcinogenic and toxic compounds such as polycyclic aromatic hydrocarbons, nicotine, cotinine, phenol, cresols, formaldehyde, and tobacco-specific nitrosamines ${ }^{1,9}$. Hence, THS exposure is not hazardfree. In addition to non-smoking adults, children are most susceptible to THS exposure because they spend more time indoors and have increased hand-to-mouth behavior, increasing their chances of exposure ${ }^{10,11}$. Given their immature respiratory and immune systems, children are more vulnerable and sensitive to the adverse effects of THS exposure in places where smoking is allowed, especially in homes ${ }^{11,12}$. Emerging studies have highlighted the potential harm of THS exposure and its association with adverse health effects. Experimental animal model studies have shown that exposure to THS is associated with reduced body weight in neonatal mice, metabolomic alterations in human reproductive cell lines, and changes in immunological parameters in the blood of experimental mice ${ }^{13,14}$. Also, it has been shown that experimentally exposing human cell lines to THS pollutants is associated with major DNA damage ${ }^{15}$. Martins-Green et al. ${ }^{16}$ reported a possible association between THS exposure and hyperactivity-related behavior in THS-exposed mice. The negative health impact of THS was further demonstrated by Wang et al. ${ }^{17}$ who have shown that THS exposure during pregnancy is associated with increased postpartum depression risk among Chinese women. Nonetheless, more studies are needed to further elucidate the health effects of THS exposure.

Increased knowledge and beliefs about the harm of ETS exposure have been reported to be associated with protective behaviors, such as smoke-free home rules and avoiding exposure to ETS ${ }^{18-21}$. Protano et al. ${ }^{22}$ have assessed the association between homesmoking rules and urinary cotinine concentrations in children, and reported that ETS exposure level (as measured by urinary cotinine concentration) increased among children as home-smoking rules were more permitting. For example, ETS exposure level was lowest among children not living with smoker(s), and was highest among children living with smoker(s) who smoke at home even in the presence of the child ${ }^{22}$. Regarding THS, few prior studies have examined the association between THS knowledge and beliefs with smoking-related preventive measures. A study by Winickoff et al. ${ }^{23}$ showed that beliefs about THS health effects on children were independently linked with strict home smoking bans. Another study concluded that beliefs of THS harm to children were associated with strict implementation of smoke-free home and car measures and increased attempts to quit smoking ${ }^{24}$. The findings of the aforementioned studies indicate that THS harm beliefs may be a critical factor in encouraging home smoking bans. Participants in a qualitative study believed that being educated about THS harms would motivate people to adopt smokefree home rules ${ }^{25}$. Nevertheless, THS is scarcely discussed in health promotion strategies and policies, and knowledge and beliefs about THS are not widely assessed globally at the population level.

In a nationally representative study sample in Kuwait, the prevalence of current (any use in the past 30-days) cigarette smoking among adults was estimated to be $39.2 \%$ among men and $3.3 \%$ among women $^{26}$. Moreover, a study conducted among high school students in Kuwait showed that 26.4\%, 25.1\%, and $20.9 \%$, of the study participants were current e-cigarette users, conventional cigarette smokers, and hookah smokers, respectively ${ }^{27}$. Moreover, in Kuwait, $45.8 \%$ of middle school students and $51.6 \%$ of high school students were reported to be exposed to household ETS $^{28}$. As a new source of passive smoking, $32.0 \%$ of high school students in Kuwait reported being exposed to electronic cigarette aerosols (vapor) in households ${ }^{27}$. Aerosols from electronic cigarettes differ in their constituents compared to combustible 
tobacco smoke; however, they still contain ultrafine particles such as volatile carbonyls, reactive oxygen species, furans, formaldehyde, and metals (cadmium, lead, nickel, tin, copper, chromium) that have been shown to adversely affect health ${ }^{29-32}$. In terms of the relevance of electronic cigarette aerosols to THS, a prior study has shown that electronic cigarettes emit submicron and ultrafine particles that can persist in the exposed environment and hence expose others to THS pollutants ${ }^{33}$. Collectively, such an elevated passive smoking exposure among children in Kuwait indicates that household THS exposure is substantial as well. To our knowledge, no prior studies have investigated parents' beliefs in Kuwait about THS harm, which is an important element that may help reduce the negative health impact of tobacco smoke exposure in children and non-smoker adults. Therefore, this study aimed to assess parents' beliefs about THS in terms of harm and persistence in the environment and to evaluate associations between parents' THS beliefs and home smoking rules.

\section{METHODS}

\section{Study setting, design, and participants}

A cross-sectional study was conducted by enrolling parents residing in Kuwait $(n=536$; aged $\geq 18$ years) using a web-based survey that was disseminated using email and social media platforms, including Twitter, Instagram, and WhatsApp. Parents with at least one child aged $<18$ years were invited to participate in the study. The enrollment of subjects started on 18 December 2020 and ceased on 27 January 2021. The snowball sampling technique, a non-probability sampling method that yields a convenience sample, was used to recruit participants. The study was approved by the Health Sciences Center Ethics Committee of Kuwait University (No. VDR/EC/3687). Completion of the questionnaire by the participants was deemed as informed consent to participate. The study was conducted in accordance with the principles and guidelines of the Declaration of Helsinki for medical research involving human subjects.

\section{Study questionnaire and variable definitions}

The study questionnaire, designed to be selfcompleted by parents, gathered information on sociodemographic data, lifestyle factors, home smoking rules, and beliefs about THS. Participants self-reported their age in years $(18-34,35-44$, or $\geq 45$; this age categorization was applied to closely resemble the distribution of the measured continuous age variable in the total study sample), highest educational attainment (high school degree or less, diploma degree, Bachelor's degree, or higher education/graduate degree), total monthly household income in Kuwaiti Dinar (KWD: $\leq 1500,1501-3000$, or $\geq 3001$; this categorization was based on the results of the "Income and Expenditure Household Survey' by the Central Statistical Bureau, Kuwait ${ }^{34}$ ), housing type (apartment, floor-through apartment, or house), nationality (Kuwaiti or non-Kuwaiti), and current governorate of residence (Al-Asimah, Hawalli, Mubarak Al-Kabeer, Farwaniya, Ahmadi, or Jahra). Moreover, parents were asked to report whether they had ever smoked tobacco products. Those who had ever smoked were further asked whether they had used any tobacco product (i.e. cigarettes, waterpipe, electronic cigarettes, or other) in the past 30 days. Hence, smoking status was ascertained as never, former (ever smoked tobacco product, but not in the past 30 days), and current (smoked tobacco product in the past 30 days). Due to the limited number of participants that were classified as former smokers $(n=28)$, we combined former and current smokers in a single group and reported them as ever smokers.

Home smoking rules were assessed by asking parents to choose which statement best describes the 'rules' of smoking inside their home: 'nobody can smoke (smoking is not allowed) inside the home', 'you can only smoke in some places inside the home', 'you can smoke anywhere (there are no rules) inside the home', or 'don't know/not sure'23. Parents who reported that smoking is not allowed in any part of their home were classified as having strict rules prohibiting smoking in their home. Parents who reported that smoking was allowed in some parts inside their home were classified as having partial rules prohibiting smoking in their home. Parents who reported that smoking is allowed anywhere inside their home or were unaware or unsure of smoking rules in their home, were classified as having no rule prohibiting smoking inside their home. Hence, the home smoking rule variable was categorized as: strict home smoking ban, partial home smoking ban, and no home smoking ban.

The Beliefs About ThirdHand Smoke (BATHS) 
scale, a standardized 9-item scale, was used to assess parents' overall beliefs about THS (referred to as: 'THS overall beliefs score' $)^{35}$. Moreover, of the nine items, five items were related to beliefs about THS impact on health (referred to as: 'THS health beliefs score') and four items were related to beliefs about THS persistence in the environment (referred to as: 'THS persistence beliefs score') ${ }^{35}$. The THS health belief items included the following statements ${ }^{35}$ : 'breathing air in a room today where people smoked yesterday can harm the health of infants and children', 'breathing air in a room today where people smoked yesterday can harm the health of adults', 'particles in rooms where people smoked yesterday can cause cancer', 'after smoking cigarette, smoke particles on skin, hair, and clothing can passed on to others through touch', and 'after touching surfaces where cigarette smoke has settled, particles can enter the body through skin'. The THS persistence belief items included the following statements: 'smoke particles can remain in a room for days', 'smoke particles can remain in a room for weeks', 'smoke particles get absorbed into furniture and walls', and 'opening windows or using air conditioners does not eliminate all smoke particles in a room'. For each of the nine items, response options were measured on a 5-point Likert scale, where parents were asked to indicate whether they strongly disagree, disagree, not sure, agree, or strongly agree. The responses were coded 1 through 5 , with 1 corresponding to a strongly disagree response and 5 corresponding to a strongly agree response. The 'THS overall beliefs score', based on 9 items, can range from 9 to 45; the 'THS health beliefs score', based on 5 items, can range from 5 to 25; and the 'THS persistence beliefs score', based on 4 items, can range from 4 to 20 . Higher scores indicate stronger beliefs about the harm and persistence of THS.

\section{Statistical analysis}

Analyses were conducted using IBM ${ }^{\circledR}$ SPSS Statistics for Windows, Version 25.0 (IBM Corp., Armonk, NY, USA) and SAS 9.4 (SAS Institute, Cary, NC, USA). The statistical significance level was set to $a=0.05$, for all association analyses. Descriptive analyses were conducted to calculate the frequencies and proportions of the categorical variables. The THS overall, health, and persistence beliefs scores, nonnormally distributed quantitative variables, were described by calculating the median and interquartile range (IQR). Chi-squared $\left(X^{2}\right)$ tests were used to assess whether the prevalence of home smoking rules (i.e. strict home smoking ban, partial home smoking ban, and no home smoking ban) differed depending on sociodemographic and lifestyle factors. Nonparametric tests were used to determine whether the median of the THS overall, health, and persistence beliefs scores differed across groups of categorical variables. The Wilcoxon rank sum test was used to compare the medians of two groups, and the KruskalWallis test was used to determine whether the medians of three or more groups differed. Moreover, the THS overall, health, and persistence beliefs scores were categorized using quartiles $(\mathrm{Q})$, where the quartile 1 (Q1) group included individuals with the lowest scores and the quartile 4 (Q4) group included individuals with the highest scores. Associations between quartiles of the THS overall, health, and persistence beliefs scores (independent variables) and home smoking rules (outcome variable: strict home smoking ban vs no home smoking ban; and partial home smoking ban vs no home smoking ban) were assessed by applying a modified Poisson regression with robust variance estimation to estimate adjusted prevalence ratios (APRs) and their 95\% confidence intervals $(\mathrm{CIs})^{36}$. Variables that demonstrated a possible association with THS overall, health, and persistence beliefs scores (independent variables) and/or home smoking rules (outcome variable) in bivariate analyses (i.e. $\mathrm{p} \leq 0.2$, as suggested by Maldonado and Greenland ${ }^{37}$ ) were simultaneously entered into the multivariable regression models. A separate regression model was used to assess the association between each of the three THS beliefs score (i.e. overall, health, and persistence THS beliefs scores) and home smoking rules, while adjusting for the effect of the aforementioned confounders.

\section{RESULTS}

In total, 536 parents residing in Kuwait with at least one child aged $<18$ years participated in the current study, of whom 132 (24.6\%) were males and 404 (75.4\%) were females (Table 1). The median (IQR) age of the study participants was estimated to be 34.0 (29-40) years. The majority of participants were aged $18-34$ years $(50.9 \%)$ and reported to have attained a Bachelor's degree (57.6\%). Ever smoking 
a tobacco product was reported by $29.7 \%$ of the study participants, with the prevalence of current smoking being $24.4 \%$ (131/536; i.e. excluding 28 former smokers). The vast majority of the participants were of Kuwaiti nationality (92.0\%). Of the total study sample, $42.0 \%$ reported having a strict home smoking ban (i.e. smoking inside their home is prohibited), $43.6 \%$ reported having a partial home smoking ban (i.e. smoking inside their home is allowed in some places), and $14.4 \%$ reported that smoking is allowed inside their home with no restrictions (Table 1). No significant difference according to sex was

Table 1. Distribution of demographic characteristics of study participants in the total study sample and according to home smoking rules

\begin{tabular}{|c|c|c|c|c|c|}
\hline & \multirow{2}{*}{$\begin{array}{c}\text { Total sample } \\
\%(n)\end{array}$} & \multicolumn{3}{|c|}{ Home smoking rules, \% (n/total) } & \multirow[b]{2}{*}{$p^{\dagger}$} \\
\hline & & $\begin{array}{l}\text { Strict home } \\
\text { smoking ban }\end{array}$ & $\begin{array}{l}\text { Partial home } \\
\text { smoking ban }\end{array}$ & $\begin{array}{c}\text { No home } \\
\text { smoking ban }\end{array}$ & \\
\hline Overall & $100(536)$ & $42.0(225 / 536)$ & $43.6(234 / 536)$ & $14.4(77 / 536)$ & - \\
\hline \multicolumn{6}{|l|}{ Sex } \\
\hline Male & $24.6(132)$ & $40.9(54 / 132)$ & $46.2(61 / 132)$ & $12.9(17 / 132)$ & 0.749 \\
\hline Female & $75.4(404)$ & $42.3(171 / 404)$ & $42.8(173 / 404)$ & $14.9(60 / 404)$ & \\
\hline \multicolumn{6}{|l|}{ Age (years) } \\
\hline $18-34$ & $50.9(273)$ & $35.9(98 / 273)$ & $49.1(134 / 273)$ & $15.0(41 / 273)$ & 0.056 \\
\hline $35-44$ & $32.5(174)$ & $48.9(85 / 174)$ & $36.8(64 / 174)$ & $14.3(25 / 174)$ & \\
\hline$\geq 45$ & $16.6(89)$ & $47.2(42 / 89)$ & $40.4(36 / 89)$ & $12.4(11 / 89)$ & \\
\hline \multicolumn{6}{|l|}{ Education level } \\
\hline High school degree or less & $8.2(44)$ & $34.1(15 / 44)$ & $43.2(19 / 44)$ & $22.7(10 / 44)$ & 0.045 \\
\hline Diploma degree $^{\#}$ & $21.5(115)$ & $34.8(40 / 115)$ & $50.4(58 / 115)$ & $14.8(17 / 115)$ & \\
\hline Bachelor's degree & $57.6(309)$ & $42.4(131 / 309)$ & $42.4(131 / 309)$ & $15.2(47 / 309)$ & \\
\hline Higher education degree & $12.7(68)$ & $57.4(39 / 68)$ & $38.2(26 / 68)$ & $4.4(3 / 68)$ & \\
\hline \multicolumn{6}{|l|}{ Smoking status } \\
\hline Never smoked & $70.3(377)$ & $49.1(185 / 377)$ & $37.1(140 / 377)$ & $13.8(52 / 377)$ & $<0.001$ \\
\hline Ever smoked (former/current)* & 29.7 (159) & $25.2(40 / 159)$ & $59.1(94 / 159)$ & $15.7(25 / 159)$ & \\
\hline \multicolumn{6}{|c|}{ Monthly household income (KWD) } \\
\hline$\leq 1500$ & 33.4 (179) & $40.2(72 / 179)$ & $46.9(84 / 179)$ & $12.9(23 / 179)$ & 0.069 \\
\hline $1501-3000$ & $45.5(244)$ & $38.5(94 / 244)$ & $43.9(107 / 244)$ & $17.6(43 / 244)$ & \\
\hline$\geq 3001$ & $21.1(113)$ & $52.2(59 / 113)$ & $38.1(43 / 113)$ & $9.7(11 / 113)$ & \\
\hline \multicolumn{6}{|l|}{ Type of housing } \\
\hline Apartment & $55.0(295)$ & $36.6(108 / 295)$ & $46.8(138 / 295)$ & $16.6(49 / 295)$ & 0.044 \\
\hline Floor-through apartment & $18.9(101)$ & $47.5(48 / 101)$ & $43.6(44 / 101)$ & $8.9(9 / 101)$ & \\
\hline House & $26.1(140)$ & $49.3(69 / 140)$ & $37.1(52 / 140)$ & $13.6(19 / 140)$ & \\
\hline \multicolumn{6}{|l|}{ Governorate of residence } \\
\hline Al-Asimah & $21.3(114)$ & $50.0(57 / 114)$ & $34.2(39 / 114)$ & $15.8(18 / 114)$ & 0.262 \\
\hline Hawalli & $35.8(192)$ & $44.3(85 / 192)$ & 42.7 (82/192) & $13.0(25 / 192)$ & \\
\hline Mubarak Al-Kabeer & $22.0(118)$ & $35.6(42 / 118)$ & $50.0(59 / 118)$ & $14.4(17 / 118)$ & \\
\hline Farwaniya & $11.2(60)$ & $41.7(25 / 60)$ & $41.7(25 / 60)$ & $16.6(10 / 60)$ & \\
\hline Ahmadi & $5.8(31)$ & $35.5(11 / 31)$ & $48.4(15 / 31)$ & $16.1(5 / 31)$ & \\
\hline Jahra & $3.9(21)$ & $23.8(5 / 21)$ & $66.7(14 / 21)$ & $9.5(2 / 21)$ & \\
\hline \multicolumn{6}{|l|}{ Nationality } \\
\hline Kuwaiti & $92.0(493)$ & $41.6(205 / 493)$ & $44.2(218 / 493)$ & $14.2(70 / 493)$ & 0.673 \\
\hline Non-Kuwaiti & $8.0(43)$ & $46.5(20 / 43)$ & $37.2(16 / 43)$ & $16.3(7 / 43)$ & \\
\hline
\end{tabular}

KWD: 100 Kuwaiti Dinar about US\$333. \# Refers to 2 years post high school education. ${ }^{*}$ Only 28 participants were classified as former smokers and were thus combined with current smokers. $\dagger$ Calculated using chi-squared tests. 
observed in the prevalence of home smoking bans $(p=0.749)$. Parents aged $18-34$ years reported the lowest prevalence of strict home smoking ban (35.9\%, $\mathrm{p}=0.056)$ compared to parents aged 35-44 years $(48.9 \%)$ and $\geq 45$ years $(47.2 \%)$ (Table 1$)$. Whereas, the highest prevalence of partial home smoking ban was seen among young parents aged $18-34$ years (49.1\%). Moreover, the prevalence of strict home smoking ban was higher among never smokers than among ever smokers ( $49.1 \%$ vs $25.2 \%, \mathrm{p}<0.001)$, whereas partial home smoking ban was higher among ever smokers than among never smokers (59.1\% vs $37.1 \%)$. Strict home smoking bans were most prevalent among participants reporting a monthly household income of $\geq 3001 \mathrm{KWD}$ ( $52.2 \%)$, subjects with a higher education degree (i.e. postgraduate degree, $57.4 \%$ ), and those living in a house (49.3\%) (Table 1).

Figure 1 shows parents' responses to each of the 9-items used to assess beliefs about THS. A large proportion of parents agreed or strongly agreed that THS harms both the health of children $(67.2 \%)$ and adults (60.6\%). Regarding whether THS particles in rooms exposed to smoking can cause cancer, 36.9\% of participants agreed or strongly agreed with this statement. Moreover, a high proportion of participants agreed or strongly agreed that smoke particles could remain for days in a room (58.9\%), whereas only $24.2 \%$ of participants believed that smoke particles could remain for weeks. The belief that smoke particles get absorbed into the furniture and walls was reported by $68.3 \%$ of the participants. Only $24.5 \%$ of participants

Figure 1. Parents' response to each of the 9-items assessed in the Beliefs About Thirdhand Smoke (BATHS) scale

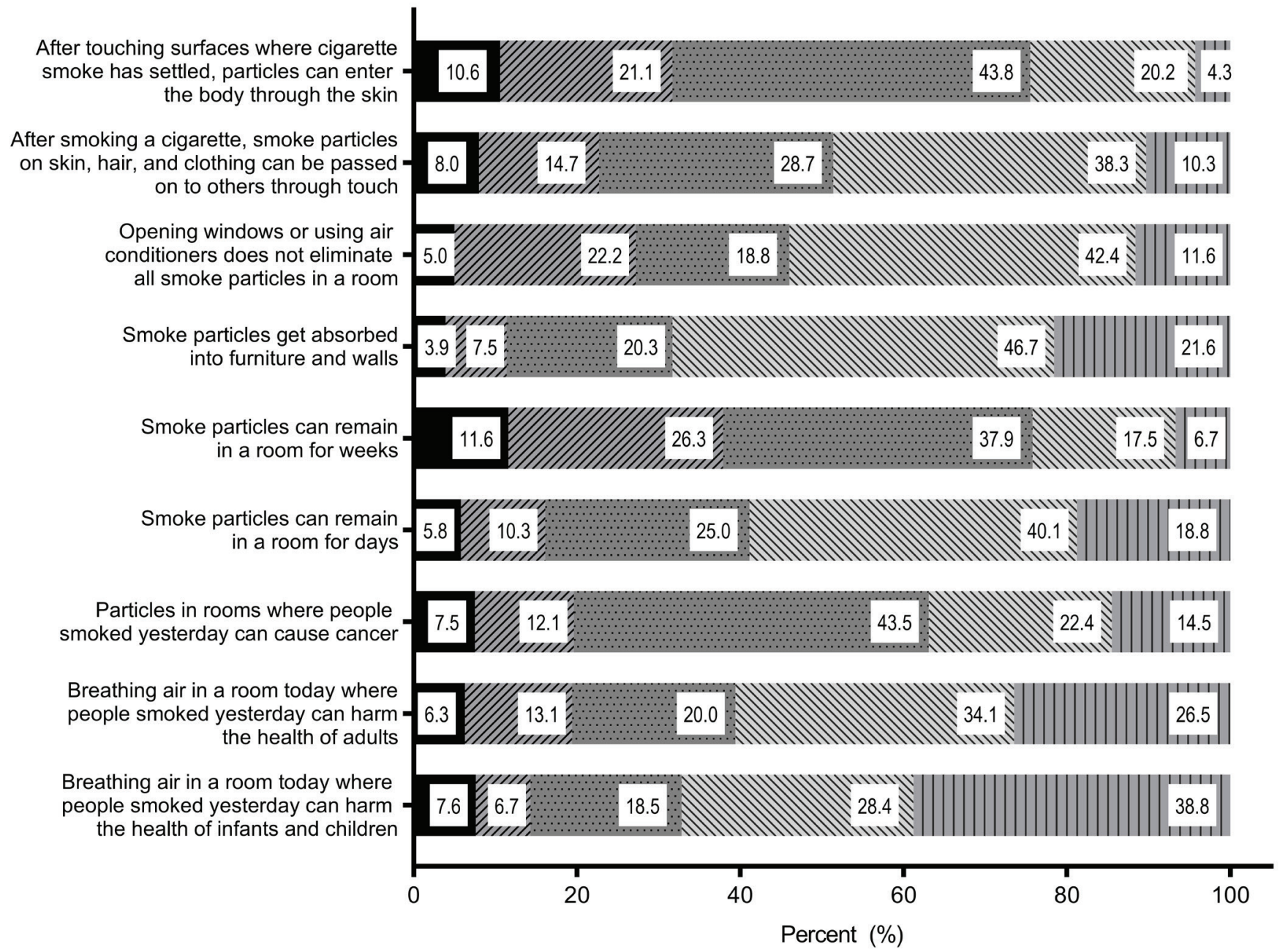

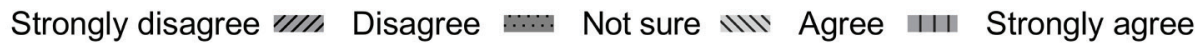


agreed or strongly agreed that dermal absorption of smoke particles through touching surfaces exposed to cigarette smoke was possible. In contrast, $48.6 \%$ of participants believed that smoke particles on the skin, hair and clothing of smokers could be passed to others through touch. More than half $(54.0 \%)$ of the participants agreed or strongly agreed that opening windows/using air conditioners does not eliminate all indoor smoke particles (Figure 1).

Results of bivariate analysis between THS overall, health, and persistence beliefs scores and participants' characteristics and lifestyle factors are shown in Table 2 . The median THS overall and health beliefs scores were higher among female than male participants, but

Table 2. Distribution of thirdhand smoke (THS) overall, health, and persistence beliefs scores across characteristics of participants

\begin{tabular}{|c|c|c|c|c|c|c|}
\hline & \multicolumn{2}{|c|}{ THS overall beliefs score } & \multicolumn{2}{|c|}{ THS health beliefs score } & \multicolumn{2}{|c|}{ THS persistence beliefs score } \\
\hline & Median (IQR) & $p *$ & Median (IQR) & $p^{*}$ & Median (IQR) & $p *$ \\
\hline Overall & $31.0(8.0)$ & - & $17.0(5.0)$ & - & $14.0(3.0)$ & - \\
\hline \multicolumn{7}{|l|}{ Sex } \\
\hline Male & $30.0(9.5)$ & 0.066 & $17.0(6.5)$ & 0.038 & $14.0(4.0)$ & 0.381 \\
\hline Female & $31.0(7.0)$ & & $18.0(5.0)$ & & $14.0(3.0)$ & \\
\hline \multicolumn{7}{|l|}{ Age (years) } \\
\hline $18-34$ & $31.0(8.0)$ & 0.163 & $17.0(6.0)$ & 0.239 & $13.0(4.0)$ & 0.024 \\
\hline $35-44$ & $31.0(7.0)$ & & $18.0(6.0)$ & & $14.0(3.0)$ & \\
\hline$\geq 45$ & $32.0(7.0)$ & & $18.0(5.0)$ & & $14.0(4.0)$ & \\
\hline \multicolumn{7}{|l|}{ Education level } \\
\hline High school degree or less & $31.0(8.5)$ & 0.001 & $18.0(5.5)$ & 0.003 & $14.0(4.0)$ & 0.003 \\
\hline Diploma degree ${ }^{\#}$ & $30.0(8.0)$ & & $17.0(6.0)$ & & $13.0(5.0)$ & \\
\hline Bachelor's degree & $31.0(8.0)$ & & $17.0(5.0)$ & & $14.0(3.0)$ & \\
\hline Higher education degree & $33.0(8.0)$ & & $19.0(5.0)$ & & $14.0(4.0)$ & \\
\hline \multicolumn{7}{|l|}{ Smoking status } \\
\hline Never smoked & $32.0(7.0)$ & $<0.001$ & $18.0(4.0)$ & $<0.001$ & $14.0(4.0)$ & $<0.001$ \\
\hline Ever smoked (former/current) & $29.0(10.0)$ & & $16.0(7.0)$ & & $13.0(4.0)$ & \\
\hline \multicolumn{7}{|c|}{ Monthly household income (KWD) } \\
\hline$\leq 1500$ & $30.0(7.0)$ & 0.011 & $17.0(4.0)$ & 0.009 & $13.0(3.0)$ & 0.051 \\
\hline $1501-3000$ & $31.0(9.5)$ & & $17.0(6.0)$ & & $14.0(4.0)$ & \\
\hline$\geq 3001$ & $32.0(6.0)$ & & $18.0(4.0)$ & & $14.0(2.0)$ & \\
\hline \multicolumn{7}{|l|}{ Type of housing } \\
\hline Apartment & $30.0(7.0)$ & 0.107 & $17.0(5.0)$ & 0.124 & $13.0(3.0)$ & 0.034 \\
\hline Floor-through apartment & $31.0(8.0)$ & & $18.0(6.0)$ & & $14.0(4.0)$ & \\
\hline House & $31.0(7.0)$ & & $18.0(5.0)$ & & $14.0(3.5)$ & \\
\hline \multicolumn{7}{|l|}{ Governorate of residence } \\
\hline Al-Asimah & $31.0(7.0)$ & 0.639 & $18.0(5.0)$ & 0.778 & $14.0(3.0)$ & 0.552 \\
\hline Hawalli & $31.0(8.0)$ & & $17.0(5.0)$ & & $14.0(4.0)$ & \\
\hline Mubarak Al-Kabeer & $31.0(7.0)$ & & $17.0(6.0)$ & & $14.0(3.0)$ & \\
\hline Farwaniya & $32.0(6.0)$ & & $18.0(5.0)$ & & $14.0(4.0)$ & \\
\hline Ahmadi & $30.0(10.0)$ & & $17.0(7.0)$ & & $13.0(3.0)$ & \\
\hline Jahra & $29.0(10.0)$ & & $16.0(4.0)$ & & $13.0(4.0)$ & \\
\hline \multicolumn{7}{|l|}{ Nationality } \\
\hline Kuwaiti & $31.0(6.0)$ & 0.655 & $17.0(5.0)$ & 0.680 & $14.0(3.0)$ & 0.925 \\
\hline Non-Kuwaiti & $30.0(9.0)$ & & $17.0(6.0)$ & & $14.0(3.0)$ & \\
\hline
\end{tabular}

KWD: 100 Kuwaiti Dinar about US\$333. IQR: interquartile range; THS: thirdhand smoke. \# Refers to 2 years post high school education. ${ }^{*}$ Calculated using the Wilcoxon rank sum test when comparing the medians of two groups, and the Kruskal-Wallis test when comparing medians of three or more groups. 
Table 3. Associations between thirdhand smoke (THS) overall, health, and persistence beliefs scores quartiles and home smoking rules

\begin{tabular}{|c|c|c|c|c|c|c|c|c|}
\hline \multirow[t]{2}{*}{$\begin{array}{l}\text { Independent } \\
\text { variablest }\end{array}$} & \multicolumn{2}{|c|}{ Total sample } & \multicolumn{3}{|c|}{$\begin{array}{l}\text { Strict home smoking ban vs No home smoking } \\
\text { ban }\end{array}$} & \multicolumn{3}{|c|}{$\begin{array}{c}\text { Partial home smoking ban vs No home smoking } \\
\text { ban }\end{array}$} \\
\hline & $n$ & $\begin{array}{c}\text { Median } \\
(I Q R)\end{array}$ & $\%(n)$ & $\begin{array}{l}\text { Unadjusted PR } \\
\quad(95 \% \text { CI })\end{array}$ & $\begin{array}{l}\text { Adjusted PR* } \\
\text { (95\% CI) }\end{array}$ & $\%(n)$ & $\begin{array}{l}\text { Unadjusted PR } \\
\qquad(95 \% \text { CI })\end{array}$ & $\begin{array}{l}\text { Adjusted PR* } \\
\text { (95\% CI) }\end{array}$ \\
\hline \multicolumn{9}{|l|}{$\begin{array}{l}\text { THS overall } \\
\text { beliefs score }\end{array}$} \\
\hline Quartile 1 & 123 & $22.0(8.0)$ & $25.2(31)$ & 1 (Ref.) & 1 (Ref.) & $55.3(68)$ & 1 (Ref.) & 1 (Ref.) \\
\hline Quartile 2 & 132 & $29.0(2.0)$ & $40.2(53)$ & $1.29(0.98-1.69)$ & $1.25(0.93-1.66)$ & $44.7(59)$ & $1.01(0.85-1.21)$ & $1.09(0.90-1.32)$ \\
\hline Quartile 3 & 144 & $32.0(1.0)$ & $40.3(58)$ & $1.28(0.98-1.68)$ & $1.26(0.95-1.68)$ & $44.4(64)$ & $1.01(0.85-1.18)$ & $1.07(0.89-1.28)$ \\
\hline Quartile 4 & 137 & $37.0(4.0)$ & $60.6(83)$ & $1.57(1.23-2.00)^{\dagger}$ & $1.48(1.12-1.96)^{\S}$ & $31.4(43)$ & $1.08(0.90-1.29)$ & $1.23(0.98-1.55)$ \\
\hline \multicolumn{9}{|l|}{$\begin{array}{l}\text { THS health } \\
\text { beliefs score }\end{array}$} \\
\hline Quartile 1 & 125 & $12.0(5.0)$ & $32.0(40)$ & 1 (Ref.) & 1 (Ref.) & $51.2(64)$ & 1 (Ref.) & 1 (Ref.) \\
\hline Quartile 2 & 151 & $16.0(2.0)$ & $29.8(45)$ & $0.95(0.74-1.23)$ & $0.90(0.69-1.17)$ & $52.3(79)$ & $0.99(0.84-1.17)$ & $1.03(0.87-1.23)$ \\
\hline Quartile 3 & 110 & $18.0(1.0)$ & $46.4(51)$ & $1.16(0.93-1.46)$ & $1.10(0.87-1.38)$ & $39.1(43)$ & $0.97(0.79-1.18)$ & $1.01(0.82-1.24)$ \\
\hline Quartile 4 & 150 & $21.0(2.0)$ & $59.3(89)$ & $1.33(1.09-1.62)^{\mathrm{s}}$ & $1.22(1.02-1.45)^{\#}$ & $32.0(48)$ & $1.05(0.87-1.25)$ & $1.09(0.91-1.32)$ \\
\hline \multicolumn{9}{|c|}{$\begin{array}{l}\text { THS persistence } \\
\text { beliefs score }\end{array}$} \\
\hline Quartile 1 & 112 & $9.0(3.5)$ & $25.0(28)$ & 1 (Ref.) & 1 (Ref.) & $53.6(60)$ & 1 (Ref.) & 1 (Ref.) \\
\hline Quartile 2 & 137 & $13.0(1.0)$ & $40.9(56)$ & $1.33(1.00-1.78)^{\#}$ & $1.26(0.94-1.70)$ & $43.1(59)$ & $1.02(0.84-1.23)$ & $1.08(0.88-1.32)$ \\
\hline Quartile 3 & 157 & $14.0(1.0)$ & $45.2(71)$ & $1.42(1.08-1.87)^{\S}$ & $1.34(1.00-1.78)^{\#}$ & $40.8(64)$ & $1.04(0.87-1.25)$ & $1.11(0.92-1.35)$ \\
\hline Quartile 4 & 130 & $17.0(3.0)$ & $53.8(70)$ & $1.65(1.26-2.14)^{+}$ & $1.55(1.17-2.05)^{\S}$ & $39.2(51)$ & $1.19(1.00-1.41)^{\#}$ & $1.23(1.04-1.45)^{\#}$ \\
\hline
\end{tabular}

PR: prevalence ratio. Cl: confidence interval. IQR: interquartile range. THS: thirdhand smoke. ${ }^{*}$ Adjusted for sex, age, smoking status, education level, housing type, and monthly household income. + A separate regression model was used to assess the association between the respective THS beliefs score and home smoking rules, while adjusting for the effect of the aforementioned confounders. \# $p<0.05$. $§ p<0.01$. $\neq p<0.001$.

males and females had comparable THS persistence beliefs scores. Moreover, the THS overall, health, and persistence beliefs scores differed according to the participants' education level and monthly household income. On average, never smokers had higher THS overall (32.0 vs $29.0, \mathrm{p}<0.001)$, health (18.0 vs 16.0 , $\mathrm{p}<0.001)$, and persistence $(14.0 \mathrm{vs} 13.0, \mathrm{p}<0.001)$ beliefs scores than ever smokers. Participants living in an apartment had lower THS persistence beliefs score than those living in a floor-through apartment or house (Table 2 ).

Table 3 shows the associations between quartiles of THS overall, health, and persistence beliefs scores and home smoking rule. In general, prevalence of strict home smoking bans increased as the quartile of THS overall, health, and persistence beliefs scores increased. For example, compared to parents in quartile 1 of the respective THS beliefs score, parents in quartile 4 of the THS overall ( $60.6 \%$ vs $25.2 \%$ ), health $(59.3 \%$ vs $32.0 \%)$, and persistence $(53.8 \%$ vs
$25.0 \%)$ beliefs scores had higher prevalence of strict home smoking bans. Adjusted analysis showed that higher THS overall beliefs score to be associated with higher prevalence of having a strict home smoking ban $\left(\mathrm{APR}_{\text {Q4 vs Q1 }}=1.48 ; 95 \%\right.$ CI: $\left.1.12-1.96\right)$ (Table 3$)$. Similarly, higher THS health $\left(\mathrm{APR}_{\mathrm{Q} 4 \mathrm{vs} \text { Q1 }}=1.22 ; 95 \%\right.$ CI: $1.02-1.45)$ and persistence $\left(\mathrm{APR}_{\mathrm{Q} 4 \mathrm{vs} Q 1}=1.55\right.$; 95\% CI: 1.17-2.05) beliefs scores were associated with increased prevalence of a strict home smoking ban (Table 3). THS overall and health beliefs scores were not associated with partial home smoking ban prevalence; however, higher THS persistence beliefs score was associated with increased prevalence of partial home smoking ban $\left(\mathrm{APR}_{\mathrm{Q} 4 \mathrm{vs} Q 1}=1.23 ; 95 \%\right.$ CI: 1.04-1.45) (Table 3).

\section{DISCUSSION}

This study assessed the beliefs of parents living in Kuwait about THS and determined how these beliefs influence home smoking rules. In total, a strict home 
smoking ban was reported by $42.0 \%$ of the participants, with the prevalence of strict home smoking bans being the lowest among young participants, subjects who reported ever smoking, and those living in an apartment. Whereas, $43.6 \%$ of the study participants reported having a partial home smoking ban, with the prevalence of partial home smoking bans being highest among young participants, ever smokers, and those living in an apartment. Only $14.4 \%$ of the study participants reported no home smoking bans (i.e. smoking is allowed anywhere in their home). The majority of participants believed that exposure to THS adversely affects the health of children and adults, and that THS particles can persist in the environment for several days. The assessed THS overall, health, and persistence beliefs scores differed according to participants' education level, household monthly income, and smoking status. In this study, we found that higher THS overall, health, and persistence beliefs scores were associated with an increased prevalence of strict home smoking bans. Only higher THS persistence beliefs score was associated with increased prevalence of partial home smoking bans. These findings provide evidence that educating parents about the harm and persistence of THS may protect children, and even non-smoker adults, from being exposed to THS inside their homes.

The prevalence of strict home smoking bans in the current report $(42.0 \%)$ was lower than prior studies' prevalence, with the enforcement of voluntary strict home smoking bans reported to be $61 \%$ in homes in Italy $^{38}, 50 \%$ in homes in the United States ${ }^{35}$, and $66.1 \%$ in homes in Poland ${ }^{39}$. Similarly, a study based on data from four countries, namely, Canada (67.8\%), the United States (60.2\%), England (59.2\%), and Australia (66.2\%), reported higher prevalence of strict home smoking bans than our study ${ }^{40}$. In addition, a study in Spain found that approximately $57.4 \%$ of households had complete indoor smokefree rules ${ }^{41}$. A study based on South African adults reported the prevalence of smoke-free homes to be $62.5 \%{ }^{42}$. Moreover, a study from Japan reported that $47.0 \%$ of respondents applied comprehensive home and car smoke-free rules ${ }^{43}$. However, a Chinese study reported a lower prevalence of strict home smoking bans $(35.2 \%)$ than our prevalence ${ }^{44}$.

Findings of the current analysis showed that ever smokers (i.e. former and current smokers) were less likely to implement a smoke-free home rule than never smokers $(25.2 \%$ vs $49.1 \%)$, whereas we found that ever smokers were more likely than never smokers to have partial home smoking bans (59.1\% vs $37.1 \%)$. In agreement with our findings, the observation of a higher prevalence of smoke-free homes among non-smokers than among smokers has been widely reported. For instance, compared to smokers, non-smokers reported a higher prevalence of smoker-free homes in the United States $(88.4 \%$ vs $26.7 \%)^{23}$, Poland $(78.9 \% \text { vs } 18.6 \%)^{39}$, Italy $(69 \%$ vs $32 \%)^{38}$, South Africa $(71.3 \% \text { vs } 25.9 \%)^{42}$, Spain (72.0\% vs $28.4 \%)^{41}$, and China $(81.7 \% \text { vs } 19.3 \%)^{44}$. An important observation is that $49.1 \%$ of never smokers in our study sample reported a strict home smoking ban, which is much less than the prevalence of smoke-free homes among non-smokers in other settings. For example, based on the aforementioned studies, $88.4 \%$ of non-smokers in the United States reported smoke-free home rules ${ }^{23}$. Similarly, $78.9 \%$ of non-smokers living in Poland reported smoker-free home rules ${ }^{39}$. Hence, increasing the awareness of nonsmokers about the adverse effects of SHS and THS exposure may help increase the prevalence of smokefree homes in Kuwait. Moreover, we observed that younger parents aged 18-34 years were less likely to implement a strict home smoking rule than older parents. This observation of an association between age and implantation of a smoke-free home rule was not observed in prior studies ${ }^{23,39}$. Furthermore, our results illustrated that subjects who received higher education (i.e. postgraduate degree) were more likely to adopt a strict smoking rule at home than subjects with less educational attainment. This observation is in agreement with a prior study that found college graduates $(86.4 \%)$ to be more likely to have a strict home smoking ban than subjects with $<12$ years of formal education $(58.7 \%)^{23}$. We also observed that subjects living in apartments $(36.6 \%)$ are less likely to have strict home smoking ban compared to those living in floor-through apartments (47.5\%) or houses (49.3\%). Such a difference might be explained by the limited/no access to private outdoor space among subjects living in apartments.

Parents' beliefs about THS were measured using the 9-item BATHS scale, which measures parents' THS overall, health, and persistence beliefs scores ${ }^{35}$. Most parents agreed or strongly agreed that THS 
exposure harms the health of children $(67.2 \%)$ and adults $(60.6 \%)$. Among a sample of adults living in the United States, $61.0 \%$ agreed that THS harms children $^{23}$. However, $91.0 \%$ of parents who were living in the United States agreed that THS exposure can harm the health of children ${ }^{24}$. In the current analysis, the calculated THS overall, health, and persistence beliefs scores differed according to the educational attainment of parents, with all of the assessed THS beliefs scores increasing as educational attainment increased. We also observed a positive association between monthly household income and the THS beliefs scores. Similar patterns of associations between parents' education level and income and THS beliefs scores measured using the BATHS scale were reported among a sample of parents in Shanghai ${ }^{45}$. The aforementioned associations indicate that parents' socioeconomic status is associated with THS beliefs scores. Moreover, never smokers in our study had higher THS beliefs scores than ever smokers. This relationship between smoking status and THS beliefs has been reported in previous studies ${ }^{35,45}$, which indicates that non-smokers hold stronger harm and persistence beliefs about THS than smokers.

In multivariable analysis, we found independent associations between quartiles of THS overall, health, and persistence beliefs scores with home smoking rules after controlling for the effect of potential confounders. The prevalence of a strict home smoking ban increased as the THS overall, health, and persistence beliefs scores increased. This observation indicates that as parents hold stronger beliefs that THS harms health and persists in the environment, they are more likely to have strict rules banning smoking inside their homes. Moreover, we only found that THS persistence beliefs score to be associated with increased prevalence of partial home smoking ban, whereas THS overall and health beliefs scores were not associated with partial home smoking bans. Overall, such beliefs can protect children and non-smoker adults from the adverse effects of passive smoking, which includes THS exposure. Drehmer et al. ${ }^{24}$ showed that parents who believed that THS exposure is harmful to children were twice as likely to have a strict smoke-free home rule as those who did not believe that THS is harmful to children. Similarly, Winickoff et al. ${ }^{23}$ demonstrated an association between having a belief that THS harms children and the presence of a strict home smoking ban. Haardörfer et al. ${ }^{35}$, using the BATHS scale, showed positive associations between the THS beliefs scores and levels of home smoking bans (i.e. no ban, partial ban, full ban). The findings of associations between beliefs about THS exposure and smoke-free homes should be considered as evidence-based knowledge. Thus, THS needs to be incorporated in health promotion and education campaigns aimed at reducing home smoking. Moreover, more strict health policies are needed to prohibit indoor smoking in public and private settings to protect children and non-smokers from the negative effects of SHS and THS. Policies may designate residential rental properties as 'smokefree property' versus 'smoke-friendly property', where non-smoker tenants can have a choice of living in a smoke-free environment.

\section{Strengths and limitations}

Our study provides information about the beliefs of parents in Kuwait about THS for the first time and explored how such beliefs are associated with home smoking rules. Nonetheless, our study has some limitations. The applied snowball sampling technique is a non-random sampling method, which may have yielded a study sample that is not representative of the total parents living in Kuwait with at least one child aged $<18$ years. Hence, our findings might not be applicable to the entire target population. Moreover, selection bias cannot be eliminated because participants needed access to a smartphone, tablet, or computer to be able to participate and complete the study questionnaire. Nevertheless, in terms of education level and income, our study sample did not substantially deviate from other randomly selected samples in Kuwait. For instance a prior study that enrolled a random sample of parents $(n=3864)$ of high school students in Kuwait reported that $42.7 \%$ of mothers and $35.8 \%$ of fathers have Bachelor's degree $^{46}$, which is lower than the reported estimate in the current report $(57.6 \%$ reported having a Bachelor's degree). Moreover, the majority of study participants of the aforementioned study sample reported a household income between 1501 and 3000 Kuwaiti Dinars $(44.5 \%)^{47}$, which is close to what was reported by participants in the current report (45.5\% reported a similar income). Hence, the enrolled study sample, to some extent, does represent the target 
population. The use of the standardized BATHS scale that measured overall, health, and persistence beliefs about THS is a major advantage of our analysis. We have assessed the type of housing (i.e. apartment, floor-through apartment, and house) without inquiring about the size of the living space and the availability of outdoor space (can be used, if available, by smokers), which are important factors that may influence home-smoking rules. The analyzed 'type of housing' variable can be a surrogate for the size of indoor space as well as having access to outdoor space; however, such a limited measurement is a further limitation in our study. Moreover, due to only 28 participants being former smokers, we combined them with current smokers in the analysis. Such a combining method may mix the independent effects of former and current smokers. We would think that former smokers might be more likely than current smokers to implement a strict home-smoking ban; however, they are less likely to be as strict as never smokers. Hence, our combined variable (i.e. ever smoked) may overestimate the prevalence of strict home-smoking. Lack of information on car smoking rules is a further limitation of our study.

\section{CONCLUSIONS}

Given that the health effects of THS exposure can be substantial, our study provides novel information about the THS beliefs of parents living in Kuwait and how such beliefs are associated with strict and partial home smoking bans. In this study, we showed that parents who hold strong beliefs about the harm and environmental persistence of THS were more likely to enforce a strict home smoking ban. Such beliefs provide a safer environment for children and non-smoker adults. Hence, health promotion campaigns aimed at reducing the negative effects of passive exposure to tobacco smoke should consider incorporating educational messages about the harm of THS and its persistence in the surrounding environment as an attempt to encourage smoke-free homes.

\section{REFERENCES}

1. Matt GE, Quintana PJ, Destaillats H, et al. Thirdhand tobacco smoke: emerging evidence and arguments for a multidisciplinary research agenda. Environ Health Perspect. 2011;119(9):1218-1226. doi:10.1289/ehp.1103500
2. Oberg M, Jaakkola MS, Woodward A, Peruga A, PrussUstun A. Worldwide burden of disease from exposure to second-hand smoke: a retrospective analysis of data from 192 countries. Lancet. 2011;377(9760):139-146. doi:10.1016/S0140-6736(10)61388-8

3. Zafar Ullah AN, Huque R, Akter S, et al. Children's exposure to second-hand smoke at home in Bangladesh: a community survey. BMJ Open. 2013;3(11):e003059. doi:10.1136/bmjopen-2013-003059

4. Protano C, Vitali M. The new danger of thirdhand smoke: why passive smoking does not stop at secondhand smoke. Environ Health Perspect. 2011;119(10):A422. doi:10.1289/ehp.1103956

5. Burton A. Does the smoke ever really clear? Thirdhand smoke exposure raises new concerns. Environ Health Perspect. 2011;119(2):A70-A74. doi:10.1289/ehp.119-a70

6. Kuo HW, Rees VW. Third-hand smoke (THS): What is it and what should we do about it? J Formos Med Assoc. 2019;118(11):1478-1479. doi:10.1016/j.jfma.2019.08.025

7. Jacob P, Benowitz NL, Destaillats H, et al. Thirdhand Smoke: New Evidence, Challenges, and Future Directions. Chem Res Toxicol. 2017;30(1):270-294. doi:10.1021/acs.chemrestox.6b00343

8. Acuff L, Fristoe K, Hamblen J, Smith M, Chen J. Third-Hand Smoke: Old Smoke, New Concerns. J Community Health. 2016;41(3):680-687. doi:10.1007/s10900-015-0114-1

9. Schick SF, Farraro KF, Perrino C, et al. Thirdhand cigarette smoke in an experimental chamber: evidence of surface deposition of nicotine, nitrosamines and polycyclic aromatic hydrocarbons and de novo formation of NNK. Tob Control. 2014;23(2):152-159. doi:10.1136/tobaccocontrol-2012-050915

10. Moya J, Bearer CF, Etzel RA. Children's behavior and physiology and how it affects exposure to environmental contaminants. Pediatrics. 2004;113(Suppl 3):9961006. Accessed 26 March, 2021. https://pediatrics. aappublications.org/content/113/Supplement_3/996. long

11. Ferrante G, Simoni M, Cibella F, et al. Third-hand smoke exposure and health hazards in children. Monaldi Arch Chest Dis. 2013;79(1):38-43. doi:10.4081/monaldi.2013.108

12. McGrath-Morrow SA, Gorzkowski J, Groner JA, et al. The Effects of Nicotine on Development. Pediatrics. 2020;145(3):e20191346. doi:10.1542/peds.2019-1346

13. Hang B, Snijders AM, Huang Y, et al. Early exposure to thirdhand cigarette smoke affects body mass and the development of immunity in mice. Sci Rep. 2017;7:41915. doi:10.1038/srep41915

14. Hang B, Wang P, Zhao Y, et al. Adverse Health Effects of Thirdhand Smoke: From Cell to Animal Models. Int J Mol Sci. 2017;18(5):932. doi:10.3390/ijms18050932

15. Hang B, Sarker AH, Havel C, et al. Thirdhand smoke causes DNA damage in human cells. Mutagenesis. 2013;28(4):381-391. doi:10.1093/mutage/get013

16. Martins-Green M, Adhami N, Frankos M, et al. Cigarette 
smoke toxins deposited on surfaces: implications for human health. PLoS One. 2014;9(1):e86391. doi:10.1371/journal.pone.0086391

17. Wang L, Fu K, Li X, Kong B, Zhang B. Exposure to third-hand smoke during pregnancy may increase the risk of postpartum depression in China. Tob Induc Dis. 2018;16(April):17. doi:10.18332/tid/87141

18. Evans KA, Sims M, Judge K, Gilmore A. Assessing the knowledge of the potential harm to others caused by second-hand smoke and its impact on protective behaviours at home. J Public Health (Oxf). 2012;34(2):183-194. doi:10.1093/pubmed/fdr104

19. Kegler MC, Malcoe LH. Smoking restrictions in the home and car among rural Native American and white families with young children. Prev Med. 2002;35(4):334-342. doi:10.1006/pmed.2002.1091

20. Dunn J, Greenbank S, McDowell M, et al. Community knowledge, attitudes and behaviours about environmental tobacco smoke in homes and cars. Health Promot J Austr. 2008;19(2):113-117. doi:10.1071/he08113

21. Sun MC, Frederic JDS. Knowledge of secondhand smoke and behaviour towards its exposure among teachers in Mauritius. Tob Prev Cessat. 2020;6(May):32. doi:10.18332/tpc/120940

22. Protano C, Andreoli R, Manini P, Vitali M. How homesmoking habits affect children: a cross-sectional study using urinary cotinine measurement in Italy. Int J Public Health. 2012;57(6):885-892. doi:10.1007/s00038-012-0354-0

23. Winickoff JP, Friebely J, Tanski SE, et al. Beliefs about the health effects of 'thirdhand' smoke and home smoking bans. Pediatrics. 2009;123(1):e74-e79. doi:10.1542/peds.2008-2184

24. Drehmer JE, Ossip DJ, Nabi-Burza E, et al. Thirdhand smoke beliefs of parents. Pediatrics. 2014;133(4):e850856. doi:10.1542/peds.2013-3392

25. Escoffery C, Bundy L, Carvalho M, et al. Third-hand smoke as a potential intervention message for promoting smoke-free homes in low-income communities. Health Educ Res. 2013;28(5):923-930. doi:10.1093/her/cyt056

26. Alali WQ, Longenecker JC, Alwotyan R, AlKandari H, Al-Mulla F, Al Duwairi Q. Prevalence of smoking in the Kuwaiti adult population in 2014: a cross-sectional study. Environ Sci Pollut Res Int. 2021;28(8):10053-10067. doi:10.1007/s11356-020-11464-x

27. Esmaeil A, Alshammasi A, Almutairi W, et al. Patterns of electronic cigarette, conventional cigarette, and hookah use and related passive exposure among adolescents in Kuwait: A cross-sectional study. Tob Induc Dis. 2020;18(July):59. doi:10.18332/tid/123499

28. Ziyab AH, Almari M, Al-Taiar A. Exposure to household secondhand smoke among adolescents in Kuwait: Results from two school-based cross-sectional studies. Tob Induc Dis. 2020;18(April):32. doi:10.18332/tid/119116

29. Ferkol TW, Farber HJ, La Grutta S, et al. Electronic cigarette use in youths: a position statement of the Forum of International Respiratory Societies. Eur Respir J.
2018;51(5):1800278. doi:10.1183/13993003.00278-2018

30. Dinakar C, O'Connor GT. The Health Effects of Electronic Cigarettes. N Engl J Med. 2016;375(14):1372-1381. doi:10.1056/NEJMra1502466

31. Bals R, Boyd J, Esposito S, et al. Electronic cigarettes: a task force report from the European Respiratory Society. Eur Respir J. 2019;53(2):1801151. doi:10.1183/13993003.01151-2018

32. Alnajem A, Redha A, Alroumi D, et al. Use of electronic cigarettes and secondhand exposure to their aerosols are associated with asthma symptoms among adolescents: a cross-sectional study. Respir Res. 2020;21(1):300. doi:10.1186/s12931-020-01569-9

33. Protano C, Manigrasso M, Avino P, Vitali M. Secondhand smoke generated by combustion and electronic smoking devices used in real scenarios: Ultrafine particle pollution and age-related dose assessment. Environ Int. 2017;107:190-195. doi:10.1016/j.envint.2017.07.014

34. Central Statistical Bureau. Income and Expenditure Household Survey, 2020. Accessed June 5, 2021. https://www.csb.gov.kw/Pages/Statistics_ en?ID=16\&ParentCatID $=1$

35. Haardorfer R, Berg CJ, Escoffery C, Bundy LT, Hovell M, Kegler MC. Development of a scale assessing Beliefs About ThirdHand Smoke (BATHS). Tob Induc Dis. 2017;15(January):4. doi:10.1186/s12971-017-0112-4

36. Zou G. A modified poisson regression approach to prospective studies with binary data. Am J Epidemiol. 2004;159(7):702-706. doi:10.1093/aje/kwh090

37. Maldonado G, Greenland S. Simulation study of confounderselection strategies. Am J Epidemiol. 1993;138(11):923936. doi:10.1093/oxfordjournals.aje.a116813

38. Gallus S, Lugo A, Gorini G, Colombo P, Pacifici R, Fernandez E. Voluntary home smoking ban: prevalence, trend and determinants in Italy. Eur J Public Health. 2016;26(5):841-844. doi:10.1093/eurpub/ckw146

39. Jankowski M, Pinkas J, Zgliczynski WS, et al. Voluntary Smoke-Free Home Rules and Exposure to Secondhand Smoke in Poland: A National Cross-Sectional Survey. Int J Environ Res Public Health. 2020;17(20):7502. doi:10.3390/ijerph17207502

40. Nahhas GJ, Braak D, Cummings KM, et al. Rules about smoking and vaping in the home: findings from the 2016 International Tobacco Control Four Country Smoking and Vaping Survey. Addiction. 2019;114(Suppl 1):107-114. doi:10.1111/add.14579

41. Lidon-Moyano C, Martinez-Sanchez JM, Fu M, et al. Secondhand smoke risk perception and smoke-free rules in homes: a cross-sectional study in Barcelona (Spain). BMJ Open. 2017;7(1):e014207. doi:10.1136/bmjopen-2016-014207

42. Ayo-Yusuf OA, Olufajo O, Agaku IT. Exposure to secondhand smoke and voluntary adoption of smokefree home and car rules among non-smoking South African adults. BMC Public Health. 2014;14(1):580. doi:10.1186/1471-2458-14-580 
43. Shojima K, Tabuchi T. Voluntary home and car smoke-free rules in Japan: a cross-sectional study in 2015. BMJ Open. 2019;9(3):e024615. doi:10.1136/bmjopen-2018-024615

44. Zheng P, Kegler MC, Berg CJ, et al. Correlates of smokefree home policies in Shanghai, China. Biomed Res Int. 2014;2014:249534. doi:10.1155/2014/249534

45. Xie Z, Chen M, Fu Z, et al. Thirdhand smoke beliefs and behaviors among families of primary school children in Shanghai. Tob Induc Dis. 2021;19(February):1-10. doi:10.18332/tid/132289

46. AlShatti KA, Ziyab AH. Pet-Keeping in Relation to Asthma, Rhinitis, and Eczema Symptoms Among Adolescents in Kuwait: A Cross-Sectional Study. Front Pediatr. 2020;8:331. doi:10.3389/fped.2020.00331

47. Ziyab AH. Prevalence of food allergy among schoolchildren in Kuwait and its association with the coexistence and severity of asthma, rhinitis, and eczema: A cross-sectional study. World Allergy Organ J. 2019;12(4):100024. doi:10.1016/j.waojou.2019.100024
ACKNOWLEDGEMENTS

The authors thank all the parents for their participation in the study.

\section{CONFLICTS OF INTEREST}

The authors have completed and submitted the ICMJE Form for Disclosure of Potential Conflicts of Interest and none was reported.

\section{FUNDING}

There was no source of funding for this research.

\section{ETHICAL APPROVAL AND INFORMED CONSENT}

The study was approved by the Health Sciences Center Ethics Committee of Kuwait University (No. VDR/EC/3687). Completion of the questionnaire by the participants was deemed as informed consent to participate. The study was conducted in accordance with the principles and guidelines of the Declaration of Helsinki for medical research involving human subjects.

\section{DATA AVAILABILITY}

The data supporting this research are available from the authors on reasonable request.

\section{AUTHORS' CONTRIBUTIONS}

KS: conceptualized the study, developed data collection instrument, performed data collection and cleaning, contributed to data analysis and interpretation, and drafted the manuscript. AHZ: contributed to study conceptualization, supervised data collection and cleaning, contributed to data analysis and interpretation, and reviewed and edited the manuscript. All authors have reviewed, revised, and approved the final manuscript.

PROVENANCE AND PEER REVIEW

Not commissioned; externally peer reviewed. 